\title{
LXVII. The absorption of $\gamma$ rays
}

\section{S. Oba}

To cite this article: S. Oba (1914) LXVII. The absorption of $\gamma$ rays, Philosophical Magazine Series 6, 27:160, 601-607, DOI: 10.1080/14786440408635128

To link to this article: http://dx.doi.org/10.1080/14786440408635128

曲 Published online: 08 Apr 2009.

Submit your article to this journal 지

Џll Article views: 4

Q View related articles $₫$

4 Citing articles: 2 View citing articles 준 
applicable without further discussion, and here 1 per cent. difference in the atomic weights should produce a difference of $\frac{1}{2}$ per cent. in the diffusion constant.

\section{Summary.}

(1) The valency of fifteen radio-elements has been deter mined by measuring their diffusion constants in acid solution. The valency thus measured directly agrees without exception with what would be expected from the character of the respective radio-elements determined by their non-separability from an element of known properties.

(2) Actinium sends triple charged ions into solution. This fact supports the view that actinium is the subsequent homologue of lanthanum.

(3) In alkaline solutions the short and long lived products of the emanation are present in a colloidal state, in agreement with the views of Paneth and Godlewski. Polonium, in very weakly acid and in neutral solution, is also present in a colloidal condition.

(4) The particles of the radio-colloids contain, in some cases, only two or three atoms.

(5) The possibility of separating chemically identical elements has been discussed.

My best thanks are due to Professor Sir Ernest Rutherford for the continued kind interest which he has taken in this research.

Nanchester, August 1913.

LXVII. The Absorption of $\boldsymbol{\gamma}$ Rays. By S. Ова, Hon. Research Fellow, University of Manchester *

$T \mathrm{~T}$ is well known that with the usual experimental arrange1 ments the absorption coefficient of the $\gamma$ rays from radium decreases with increased thickness of absorber. This result has generally been ascribed to the heterogeneity of the primary rays. The softer constituents are supposed to suffer a greater amount of absorption and scattering, so that the beam as a whole becomes harder. It has also been observed that the $\gamma$ rays scattered by matter are softer than the primary rays, and this result was explained by Florance $\dagger$ on the supposition that the softer constituents of the original $\gamma$ rays are more easily scattered. Gray $\ddagger$, however, has

* Communicated by Sir Ernest Rutherford, F.R.S.

† Florance, Phil. Mag. xx. p. 921 (1910).

\pm Gray, Phil. Mag. xxvi. p. 611 (1913). 
concluded that in the scattering of $\gamma$ rays, the rays undergo a change in quality, becoming softer on scattering. The object of the present experiments was to try to investigate whether or not $\gamma$ rays are changed in their quality by passing through matter. For this purpose the absorption by aluminium and iron was determined both for the primary $\gamma$ rays of radium and for the rays after passage through different thicknesses of hardening materials such as copper, tin, and lead, since it is known that these metals apparently decrease the absorption coefficient in aluminium of $\gamma$ rays which have passed through them.

The experimental arrangement is shown in fig. 1 . The Fig. 1.
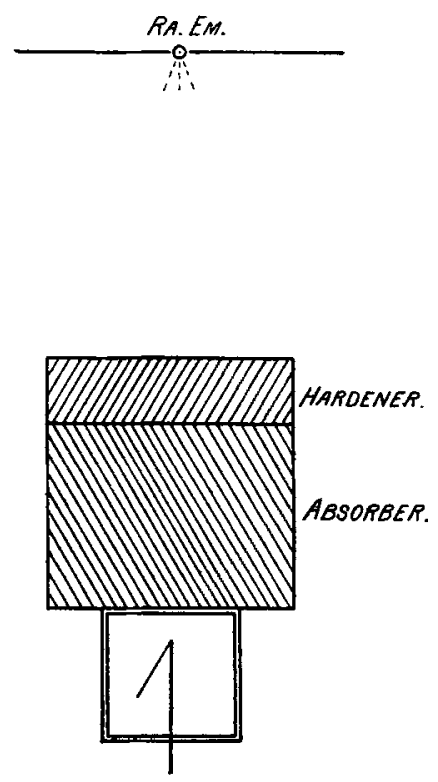

$\gamma$ rays from the source of radium emanation in equilibrium with its products passed through the hardener and the absorber, aluminium or iron, and into the electroscope below. The radium emanation was enclosed in a small glass tube, and was suspended by strings $50 \mathrm{~cm}$. above the middle of the electroscope. It could therefore be considered as a point source, and practically no correction was necessary for the oblique passage of the rays through the absorptionsheets. The absorbers and hardeners consisted of plates of equal size, $20 \mathrm{~cm}$. square, projecting $4 \mathrm{~cm}$. beyond the side walls of the electroscope. The hardeners were placed so as to rest on the absorber. The top of the electroscope was 
closed by a thin sheet of the same material as the absorbing sheets. The walls and base, however, were of lead $9.5 \mathrm{~mm}$. thick to keep out soft scattered radiations. The windows consisted of glass plates $8 \mathrm{~mm}$. thick, which were protected by lead cylinders $9 \mathrm{~mm}$. thick. A very small sulphur bead was used for the leaf-suspension, so that constant readings of the leak were obtained. The experiments were carried out in the centre of a large room, all substances from which scatter ed radiation might possibly arise being at least 2 metres distant from the electroscope.

The results are given in Tables I. and II. and shown in

TABLE I.-Al Absorbers.

\begin{tabular}{|c|c|c|c|c|c|c|}
\hline Hardeners. & \multicolumn{6}{|c|}{ Values of $\frac{\mu}{\mathrm{D}} \times 100$} \\
\hline None ........... & $9 \cdot 57$ & $4 \cdot 27$ & $4 \cdot 23$ & $4: 24$ & $4 \cdot 23$ & \\
\hline $2.4 \mathrm{~cm} . \mathrm{Cu} \ldots \ldots$ & $3 \cdot 58$ & $3 \cdot 85$ & $4 \cdot 02$ & $4 \cdot 03$ & 4.04 & \\
\hline $2.5 \mathrm{~cm} . \mathrm{Sn} \ldots .$. & $3 \cdot 18$ & $3 \cdot 51$ & $3 \cdot 71$ & $3 \cdot 83$ & $3 \cdot 81$ & \\
\hline$\cdot 2 \mathrm{~cm} . \mathrm{Pb} \ldots .$. & $3 \check{54}$ & 375 & $3 \cdot 85$ & $3 \cdot 96$ & $3 \cdot 99$ & \\
\hline $1.1 \mathrm{~cm} . \mathrm{Pb} \ldots$. & $2 \cdot 92$ & $3 \cdot 21$ & $3 \cdot 41$ & $3 \cdot 61$ & $3 \cdot 64$ & \\
\hline $2.0 \mathrm{~cm} . \mathrm{Pb} . . .$. & $2 \cdot 77$ & $3 \cdot 15$ & $3 \cdot 23$ & $3 \cdot 41$ & $3 \cdot 48$ & \\
\hline $2.9 \mathrm{~cm} . \mathrm{Pb} \ldots .$. & $2 \cdot 67$ & 3.01 & $3 \cdot 22$ & $3 \cdot 30$ & $3 \cdot 38$ & \\
\hline $3.8 \mathrm{~cm} . \mathrm{Pb} \ldots .$. & $2 \cdot 52$ & $2 \cdot 92$ & $3 \cdot 15$ & $3 \cdot 27$ & $3 \cdot 35$ & \\
\hline $\begin{array}{c}\text { Thickness of } \\
\text { Absorbers. }\end{array}$ & $\cdot 2$ & & & & & \\
\hline
\end{tabular}

TABLE II.-Fe Absorbers.

\begin{tabular}{|c|c|c|c|c|c|c|c|c|c|}
\hline Hardeners. & \multicolumn{9}{|c|}{ Values of $\frac{\mu}{D} \times 100$} \\
\hline None ........... & \multicolumn{2}{|c|}{$4 \div \check{3}$} & \multicolumn{2}{|c|}{$4 \cdot 28$} & $4 \cdot 20$ & $4 \cdot 13$ & 4.02 & \multicolumn{2}{|l|}{3.95} \\
\hline $7.5 \mathrm{~cm} . \mathrm{Al} \ldots .$. & \multicolumn{2}{|c|}{4.58} & \multicolumn{2}{|c|}{$4 \cdot 21$} & $4 \cdot 08$ & $4 \cdot 02$ & 397 & \multicolumn{2}{|c|}{$3 \cdot 94$} \\
\hline $2.4 \mathrm{~cm} . \mathrm{Cu} \ldots .$. & \multicolumn{2}{|c|}{$4 \cdot 16$} & \multicolumn{2}{|c|}{$4 \cdot 11$} & 4.02 & 4.01 & 3.93 & \multicolumn{2}{|l|}{3.92} \\
\hline $2.5 \mathrm{~cm} . \mathrm{Sn} . . .$. & \multicolumn{2}{|c|}{$3 \cdot 56$} & \multicolumn{2}{|c|}{$3 \cdot 84$} & $3 \cdot 89$ & $3 \cdot 90$ & 389 & \multicolumn{2}{|l|}{$3 \cdot 89$} \\
\hline $.2 \mathrm{~cm} . \mathrm{Pb} . . .$. & \multicolumn{2}{|c|}{$3 \cdot 83$} & \multicolumn{2}{|c|}{$3 \cdot 96$} & $3 \cdot 98$ & 3.97 & 3.96 & \multicolumn{2}{|c|}{3.92} \\
\hline $1.1 \mathrm{~cm} . \mathrm{Pb} \ldots .$. & \multicolumn{2}{|c|}{\begin{tabular}{l|l|l}
$2 \cdot 91$ & $3 \cdot 37$
\end{tabular}} & \multicolumn{2}{|c|}{$3 \cdot 53$} & $3 \cdot 67$ & 376 & $3 \cdot 78$ & \multicolumn{2}{|l|}{383} \\
\hline $2.0 \mathrm{~cm} . \mathrm{Pb} \ldots .$. & $2 \cdot 79$ & $3 \cdot 15$ & \multicolumn{2}{|c|}{$3 \cdot 39$} & 3.57 & $3 \cdot 70$ & $3 \cdot 72$ & \multicolumn{2}{|l|}{$3 \cdot 76$} \\
\hline $2.9 \mathrm{~cm} . \mathrm{Pb} \ldots .$. & \multirow{2}{*}{$\begin{array}{l}270 \\
2 \cdot 71\end{array}$} & 3.07 & & $3 \cdot 32$ & 3.51 & $3 \cdot 64$ & $3 \cdot 68$ & $3 \cdot 72$ & \\
\hline $3.8 \mathrm{~cm} . \mathrm{Pb} \ldots$. & & 3.04 & & $3 \cdot 29$ & $3: 50$ & $3 \cdot 61$ & $3 \cdot 67$ & 370 & \\
\hline $\begin{array}{c}\text { Thickness of } \\
\text { Absorbers. }\end{array}$ & 2 & 1 & 2 & & & 3 & 3 & 0 & $2 \mathrm{~cm}$. \\
\hline
\end{tabular}


figs. 2, 3,4, and 5. Table I. refers to aluminium as absorber and Table II. to iron. The aluminium used was of density $z \cdot 70$ and was practically pure; and for iron, sheets of mild steel of density 7.7 were used. In the first column of either table

Fig. 2.

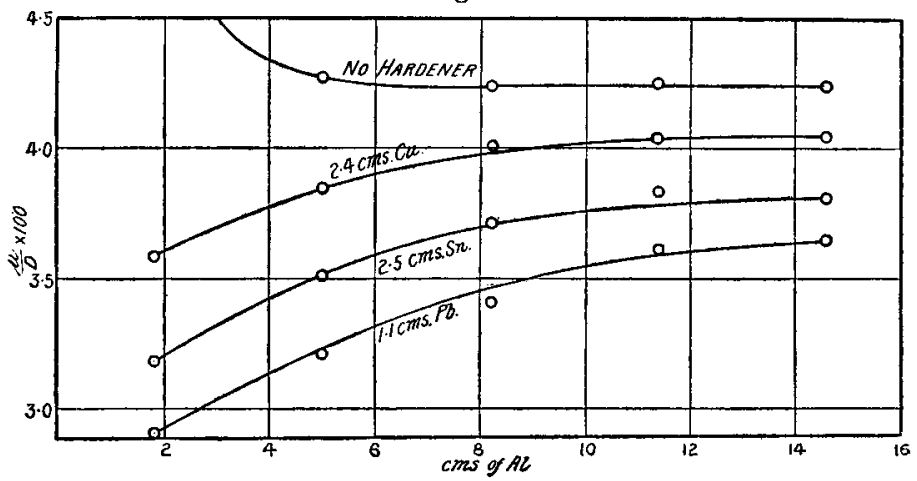

Fig. 3.

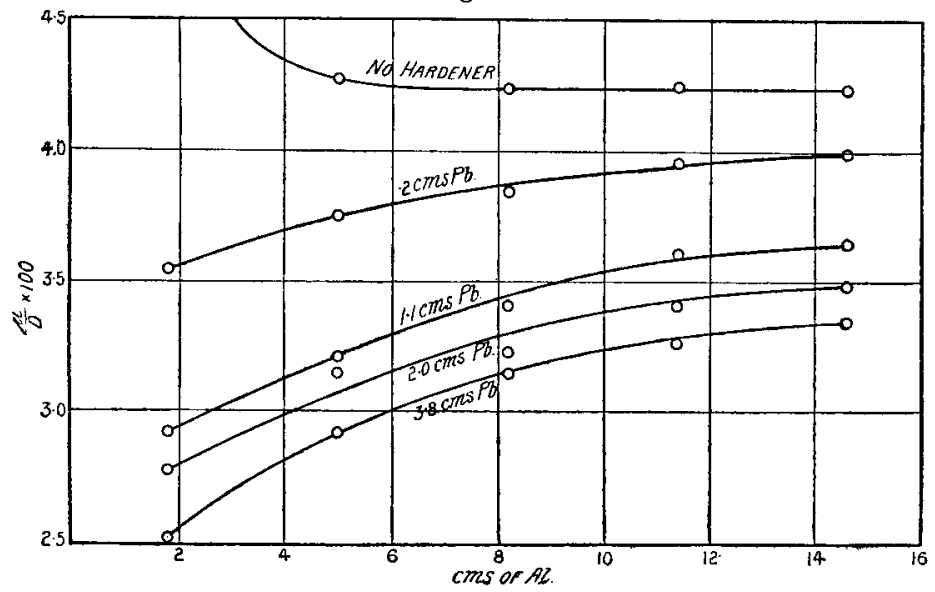

the material and thickness of the hardener are given. The thicknesses of $2 \cdot 4 \mathrm{~cm}$. copper, $2.5 \mathrm{~cm}$. tin, $1 \cdot 1 \mathrm{~cm}$. lead were chosen, because they have about the same total absorption. The remaining columns give the values of $\frac{\mu}{D} \times 100$, where $D$ is the density of the absorber and $\mu$ is the absorption coefficient calculated by the equation

$$
\mathrm{I}_{1} / \mathrm{I}_{2}=e^{\mu\left(x_{2}-x_{1}\right)}
$$


In this equation $I_{1} / I_{2}$ is the ratio of ionizations in the electroscope when thicknesses $x_{1}$ and $x_{2}$ are used. The thicknesses are given in the bottom row of the tables.

Fig. 4.

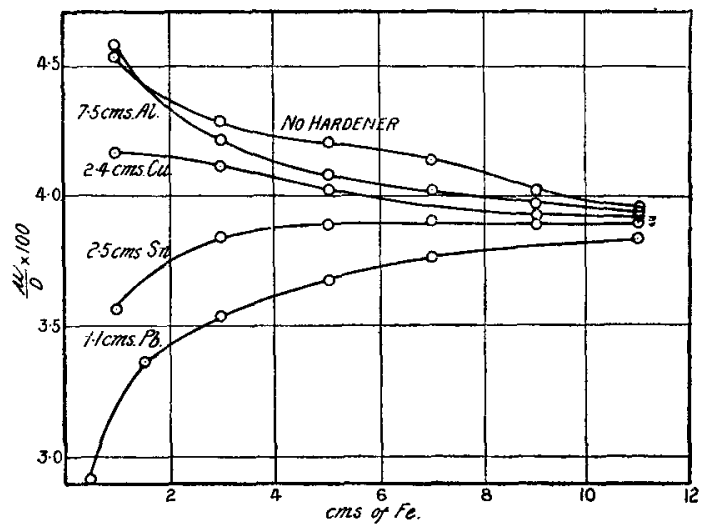

Fig. 5.

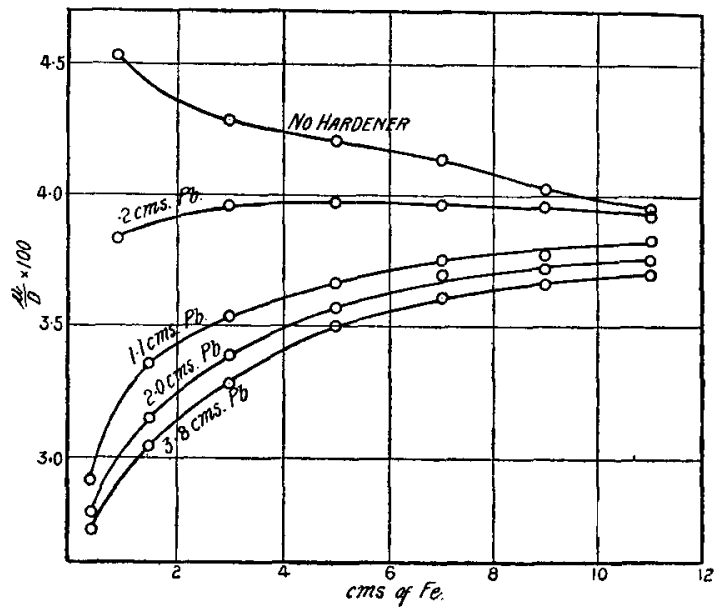

As will be seen from the curves, the results may be summarized as follows :-

(1) The absorption coefficient in aluminium for the primary $\gamma$ rays decreases gradually with increasing thickness up to $6 \cdot 6 \mathrm{~cm}$. aluminium, and is then practically constant up to $16 \mathrm{~cm}$., while that in iron continually decreases with increasing thickness.

Phil. Mag. S. 6. Vol. 27. No. 160. April 1914. 2 S 
(2) The material through which $\gamma$ rays were first passed acts always to harden the rays. This is seen by the fact that the values for $\mu / D$ given in the first row are always greater than those in the same column in any other row. The case of aluminium hardener for thicknesses of iron between $\cdot 2$ and $2 \mathrm{~cm}$. appears an exception, but the difference in this case is almost within the experimental error.

(3) The decrease of the value of $\mu / \mathrm{D}$ becomes more pronounced for larger thicknesses of the absorber, but the decrease appears to tend to a limiting value. This result is seen from the value of $\mu / D$ in the same column for different thicknesses of lead as hardıner. This effect becomes more marked with increasing difference of atomic weights of the hardener and the absorber.

(4) The $y$ rays which have been hardened become gradually softer by passing through increased thickness of absorber. Moreover, particularly in the case of iron, it is possible that the hardened $\gamma$ rays may tend with large thickness of absorber to the same penetrating power as that to which primary $\gamma$ rays tend.

As has already been stated, the hardening of $\gamma$ rays may be ascribed to the heterogeneity of the primary $\gamma$ rays and a greater amount of absorption and scattering of the softer constituents. According to the analysis of Rutherford and Richardson*, the $\gamma$ rays dealt with in these experiments will be the easily absorbed rays from $\mathrm{RaB}$ with $\mu=\cdot 51 \mathrm{~cm} .^{-1}$ aluminium, and the penetrating rays from $\mathrm{RaC}$ with $\mu=\cdot 115 \mathrm{~cm}$. $^{-1}$ aluminium. After either $8.5 \mathrm{~cm}$. aluminium, $1.5 \mathrm{~cm}$. lead, $3.0 \mathrm{~cm}$. iron, $2.7 \mathrm{~cm}$. copper, or $3.3 \mathrm{~cm}$. tin, the ionization due to $\mathrm{RaB} \gamma$ rays will be less than 1 per cent. of that due to the rays from $\mathrm{RaC}$. We may consequently take these thicknesses as a measure of the range over which we may expect that hardening will be evident.

It will be seen, however, that the various effects cannot be completely explained as due to the soft radiations from $\mathrm{RaB}$. For in the first place this will not explain the softening effect referred to in (4) above. Further, on such an hypothesis it follows that when the soft $\mathrm{RaB}$ rays are removed by absorption, the absorption coefficient of the remaining radiation should be the same and independent of the, so-called, hardener.

It must be remembered that the absorption coefficient $\mu$ being calculated from the equation

$$
I_{1} / I_{2}=e^{\mu\left(x_{2}-x_{1}\right)},
$$

* Rutherford \& Richardson, Phil. Mag. xxv. p. 721 (1913). 
the effects of both true absorption and scattering are superposed. However, it is generally supposed * that the softer constituents of $\gamma$ rays are more easily scattered than the harder ones, so that scattering gives no ready explanation of the softening obtained in these experiments.

It is possible that softening may be due in some way to the effect of excited $\gamma$ rays in the absorption-sheets-i. e., a transformation of part of the original $\gamma$ rays. Such excited rays will be in all cases softer than the rays producing them, and the issuing rays will reach a state of equilibrium when the proportion of primary rays and of softer excited rays has a certain definite value. In the case of aluminium absorber, for example, when the rays have previously passed through a hardener of high atomic weight, they will have been robbed of the greater part of the soft constituents, so that as they pass through the aluminium more and more soft radiation will be excited until equilibrium is established. The absorption coefficient should therefore increase to a constant value. The numbers given in the tables tend to support this conclusion.

The question next arises as to whether, when this supposed equilibrium has been established, the absorption coefticient has the same value independent of the hardener. Leaving out of consideration the rays from $\mathrm{RaB}$, this obviously ought to be the case if the rays from $\mathrm{RaC}$ are strictly homogeneous, $i$. e. consist of rays of one wave-length only. If the rays, for example, consist of two homogeneous beams of nearly equal wave-length, as the experiments of Moseley $†$ suggest, the hardeners might be expected to show some selective effect which would permanently alter the absorption properties of the beam. The range of thickness used in these experiments is not large enough to decide the question definitely, although the results with At appear to be in favour of the latter hypothesis.

In conclusion I desire to express my best thanks to Professor Sir Ernest Rutherford, at whose suggestion these experiments were carried out.

* Florance, loc. cit.

$\dagger$ Moseley, Phil. Mag. xxvi.p. 1024 (1913). 